mention of the extreme courtesy and kindness shown to me by the Austrian physicists, in particular by Director Prof. Stefan Ileier and Prof. Heinrich Mache, and the other gentlemen associated with this institute, throughout the period of $\mathrm{my}$ confinement here since the beginning of the war. They have stood by me through thick and thin, and were never weary in doing what they could to alleviate the strain of life under such unusual conditions. Thanks to their intervention on $\mathrm{my}$ behalf, I was given every facility for continuing my research work in the institute, and I have been at all times aided and stimulated in my work by their helpful criticism and encouraging interest.

Robert IV. LAWSON,

Formerly Pemberton Fellow of the University of IJurham.

Vienna Radium Institute, January 5.

\section{Ripple Marks due to High Pressure}

WhILE in London and examining the German guns in the Mall, I came across one with a burst shell in its breech, which is probably a unique curiosity, and possibly of value to geologists and others who are interested in the flow of solids. The shell seems to have burst while being loaded into the gun, and, although it is well opened out, only a small portion is missing. The retained pieces are of interest, for on their inner surfaces they are covered with a large number of small patches of very fine ripple marks. These must have been produced under the intense pressure of the explosion, for it is well known that the insides of shells are turned smooth, polished, and varnished. It is, of course, difficult to say whether a study of these ripple marks will prove of scientific value, but seeing that the gun and its shell are probably exposed to the rain, and as these unique ripple marks may soon corrode awar, I should like to suggest that this particular gun and its shell should be protected against further injury by being removed to a geological museum, or, perhaps, to the Lnited Service Institution.

C. E. Stromeyer.

Lancefield, West Didsbury, February 6.

\section{WAR NEUROSES AND "MTRACLE" CURES}

$\mathrm{I}$ a London daily paper there appeared recently a dramatic account of a blind Italian soldier suddenly recovering his sight at the door of the church where his bride awaited him. It is not generally known that similar "miracles" occur in this country, and the present writer has been fortunate in witnessing them in considerable number. A brief account of these conditions where the disability is rapidly curable is not without interest, for the war has produced thousands of such cases, and it is a startling fact that many sufferers have been discharged from the Army as "permanently unfit" who might otherwise be doing useful work. To remedy this state of affairs several neurological hospitals have been established, where the study and treatment of war neuroses can be carried out. The recognition that certain disablements are partly or wholly functional is of the greatest importance, for what at first might appear a hopeless condition becomes one that is curable, or, at any rate, can be markedly alleviated. Much original work on this subject has been done by Babinski, in Paris, and by
Lt.-Col. Hurst, at Seale Hayne Neurological Hospital, Newton Abbot. Some interesting statistics were recently completed at the latter institution. It was found that the average length of time during which one hundred soldiers had been completely incapacitated owing to disabled legs or arms was eleven months. The average length of time taken to cure ninety-six of these was fiftyfour minutes. Of the remaining four, one took one month, two were cured in three weeks, while the fourth required four days before recovery was obtained. The rapidity of the cure was due to the fact that the disabilities were recognised as being not organic, but functional, in character before treatment was carried out.

The origin of a functional disability in a soldier has both a physical and a psychical foundation. Few, if any, cases have been recorded as the result of the fighting in South Africa, 1899-1902. The conditions, however, under which the soldier has fought in the present war have been wholly different.

Trench warfare for prolonged periods under the most adverse climatic conditions, the high explosives causing concussion and burial, profound exhaustion following continued marching and fighting, with all the accompanying revolting sights of war, the strain of responsibility, and the suppression of emotions, are only some of the factors to be borne in mind with regard to the causation of nervous instability. It is worthy of note that there is frequently no history whatever of previous nervous trouble in the soldier who eventually succumbs to the stress and strain of military service. The ordeal through which he has passed tends to make him more impressionable or suggestible, and symptoms of hysteria are liable to supervene.

At Seale Hayne Hospital the term "hysteria" is used to describe any disability produced by auto- or hetero-suggestion which is curable by psychotherapy, by which is meant the treatment by explanation to the patient as to how the abnormal condition was brought about, and how it can be cured. His confidence must be obtained, and the explanation made simple enough for him to understand. This may be followed up, in certain cases, by re-education of muscles, active and passive movements, and persuasion. This definition will be more readily understood if a few cases, or types of cases, frequently met with are very briefly described.

A soldier sprained his ankle and immediately afterwards was rendered unconscious by the explosion of a shell. On recovering consciousness he found he had lost the power in his legs. The concussion or shock had, for the time, paralysed him, and there may have been some actual damage to his spinal cord. The time came, however, when these organic changes had passed away; but the patient was convinced in his own mind that he was permanently injured, and had given up trying to walk properly. Eight months after the onset of his symptoms the loss of power and the drop foot were recognised as being func- 
tional in nature, and he was admitted to Seale Hayne Hospital. The condition was explained to him, the muscles of the leg were re-cducated, and, with a little persuasion, he was able to run without noticeable limp in a quarter of an hour's time.

A very important class of case is where the soldier has received a bullet wound in the arm or hand, and months later the whole limb may be found paralysed. The hand may be absolutely flaccid, or the fingers have become stiff and rigid, smooth, blue in colour, and even wasted. It was recognised that the disability was out of proportion to the wound, and it was until recently looked upon by many as the result of reflex irritation.

It has been found, however, that these cases vield surprisingly quickly to psychotherapy. The hysterical, flaccid paralysis occurs where the pitient is convinced that he is paralysed and has given up trying to use his muscles. There may have been a temporary loss of power with a splint applied for an unnecessary length of time, or the man may have found at first that he experienced less pain if he kept his limb absolutely motionless.

The spastic paralysis of a hand or arm is frequently explained by the patient contracting both his flexor and extensor muscles at the same time. The more he tries to bend his fingers, the more rigid they become. The cause of the apparent trophic changes is due to the altered blood supply brought about by the lack of movement in the former casc, and by the continued spasm in the other. It is of interest to note that a hand thrown completely out of action for a year or more may recover its function after a few minutes' treatment.

Many soldiers have been invalided out of the Army with a high percentage of disability as a result of gats poisoning, though many of these are quickly curable by appropriate treatment.

The commonest symptoms persisting after this injury are loss of voice, blindness, and romiting. liny one of these conditions may be met with many months after the original onset. When a gas shell explodes, in addition to possible injuries from concussion, the gas is liable to set up inflammation of the larynx, intense irritation of the eyes, and vomiting from the absorption of the poison in the stomach. After three or four weeks these symptoms have in most cases disappeared. When, therefore, many months later, the patient is still whispering, the diagnosis of hysteria should at once be considered.

The man during the acute stage of laryngeal ir ritation hats been unable to speak, and rightly may not have attempted to do so. The frequent examinations and the treatment by inhalations and sprays convince him still further that his condition is a serious one; he erentually loses control over the musculature of his vocal apparatus, and is content to whisper. Here, ayain, with explanation and persuasion, he recovers his voice in a few minutes. Scores of such cases are on record at Seale Hayne Hospital. In a series of sixtyseven consecutive cases it was found that the average length of time they had been under treatnient, before admission there, was 205 days- the maximum being nineteen months, and the minimum two weeks. These were all rapidly and permamently cured, the majority taking only a few minutes' time.

Hysterical blindness, following inflammation of the (anjunctiva, is usually caused by spasm or flaccid paralysis of the muscles of the eyelids, just as in those of the arm after a wound. In this condition, however, the mechanism of accommodation or focussing hats also been affected. Bramatic cases of cure have been obtained of this condition, and no doubt the one quoted at the beginning of this article was one of these.

The writer was fortunate in secing a casc treated by Lt.-Col. Hurst and Capt. Gill. The patient in question had been blind since 1914 as the result of an explosion in France. At the end of 1918 a doctor eventuaily recognised the condition as probably functional in nature, and found that the interior of the eyeball was normal. The pensioner, with all the appearance of the typical street beggar, was led up to hospital. Is the result of his four years' blindness his hearing and intelligence had been affected, and he appeared extrencly dull-witted. Twenty-four hours later this mati was scarcely recognisable, for, with the recovery of his sight, his power of hearing also returned, and he appeared alert and happy. In this case the recovery was not instantaneous, for, wwing to the length of time his eyes had been functionless, some hours clapsed before his pupil reflex and accommodation acted normally.

Persistent romiting after gas poisoning maY be explained as a hysterical perpetuation of sympfoms, and has been found readily amenable to psychotherapy.

The bent back after burial from explosion, where thice are no symptoms of oryanic disease, although the patient persists in walking like an old man with the aid of two sticks, is a condition not infrequently met with. He is convinced he is umable to stand erect, in spite of the fact that there is no curvature of the spine when he is ly ing in the recumbent position. If persuasion and explanation fail in bringing about recovery, I.t.-Col. Hurst adopts the plan of making the paticnt lie upon a board with a foot-piece. This is radually raised to a right angle, and the patient, who finds himself standing in the erect position... the first time, pernaps, for many months-is told 10 walk forward. The rapidity of the cure, its apparent simplicity, and the surprise of the patient suive rise to a situation not without a certain element of humour.

These are only a few examples of war neuroses. betails of treatment depend upon the individual case, but it may be added that the atmosphere of cure that prevails in a neurological hospital is a most powerful factor in recovery. A disabled soldicr, coming in contact with others already cured, becomes more hopeful about his own condition, and is the more likely to derive bencfit from the treatment adopted. 
The object of this communication is to direct attention to the fact that thousands of soldiers, whose disabilities are curable, have been discharged from the Army. Treatment is necessary to enable the pensioner to return to useful civil employment and to save the State from vast exFenditure in unnecessary pensions. A. $R$.

\section{THE P'ROPOSED UNIVERSITY FOR THE EAST MIDLANDS.}

'THE movement for securing a charter for University College, Nottingham, with the view of making the College the seat of a University for the Fast Midlands, has been carried further forward an important stage. A large conference of representatives of the counties of Derby, Leicester, Lincoln, Northampton, Nottingham, and Rutland was held in the Grand Jury Room of the Guildhall, Nottingham, on Thursday, January 9. The Duke of Portland, who is the president of University College, took the chair, and the meeting included representatives of the leading civic and educational bodies and institutions throughout the whole area.

The population concerned forms a well-marked yeographical unity. It is concentrated, roughly speaking, in an ellipse, with its major axis stretching north and south from Mansfield to Northampton, and its minor axis east and west, with Nottingham at the northern focus. The nearness-half an hour by rail of Derby, Leicester, and Nottingham will render possible the interchange of students and teachers in a specially economical manner. And the remoter centres of population, such as Lincoln and Northampton, are within easy reach of one at least of the cities already named.

For the present, indeed, University College, Nottingham, and the Midland Agricultural College are the only institutions within the area which, in a systematic manner, provide instruction and pursue research of the highest standard. And the centre of the administration of the University will be at Nottingham. But there are in existence or immediately contemplated a considerable number of institutions providing instruction of a special character, which will become integral parts of the new University, ranging through various degrees of affiliation to the position of schools in the University. Schools of engineering; of lace, and of hosiery will, it is expected, take their respective places on a footing like that of the existing Agricultural College. Plans of a more ambitious character, involving the establishment of colleges of pure science and of arts, are also being developed. The proposed University, therefore, will furnish a type of a federal character in so far as the various schools rise towards, and obtain, recognition.

The movement is thus organic to the soil, and is not an adventitious growth. Amid local differences there is a similarity of social conditions and temperament which will bring a high degree of co-operation within reach. This co-operation may already be found in the joint foundation of the Agricultural College, in the East Midland Educational Union, and in the East Midland District of the Workers' Educational Association. But no more hopeful omen for the realisation of the proposed University could have been anticipated than the unanimity with which, on January 9, the large and representative conference first affirmed the principle in view: "The need for a University providing university and advanced technical education, and promoting scientific research" for the East Midland area, and then, in the second place, outlined the committee which should take the next steps required.

With the proposed foundation, the establishment of a University in each province will be nearly complete. And such is the richness of our English tradition, human and material, that the more recent foundations may look forward to gaining some of that atmosphere which lends a magical stimulus to the studies of our two most ancient Universities. Of the local wealth of which the new University should be the guardian, two instances may suffice, one for arts, and one for science. By a happy accident, not so many years ago, the famous Leicester Codex of the New Testament was rescued from obscurity and careless handling, and is now secure in the munimentroom of the Town Clerk of Leicester.

In Nottingham, for the lack of a proper environment, the remarkable mathematical genius of George Green displayed itself partly in vain. His epoch-making essay, "On the Application of Mathematical Analysis to the Theories of Electricity and Magnetism,"' was published in Nottingham in 1828 by subscription. In the preface the youthful author expressed the hope that "the difficulty of the subject will incline mathematicians to read this work with indulgence, more particularly when they are informed that it was written by a young man, who has been obliged to obtain the little knowledge that he possesses at such intervals and by such means as other indispensable avocations, which offer but few opportunities of mental improvement, afforded." 'The hope was vain. To quote the ninth edition of the "Encyclopædia Britannica": "The work of Green, which contained these fine researches, though published in 1828 , escaped the notice not only of foreign, but also even of British, mathematicians; and it is a singular fact in the history of science that all his general theorems were rediscovered by Sir William Thomson, Chasles, and Sturm and Gauss." Some years ago, at the instance of my colleague, Prof. E. H. Barton (to whom, himself a local mathematician, the Lniversity College is proud to have furnished the opportunities which Green lacked), I gathered from Miss Green some interesting particulars about her distinguished father; and these particulars were forwarded to Sir Joseph Larmor. I cannot imagine a more impressive argument for the foundation of the new University than a careful consideration of the biography of George Green. The traveller to Nottingham from the south can 